\title{
Iron Oxide Nanoparticles Modified with Carbon Quantum Nanodots for the Stabilization of Palladium Nanoparticles: An Efficient Catalyst for the Suzuki Reaction in Aqueous Media under Mild Conditions
}

\author{
Mohammad Gholinejad, ${ }^{*[a]}$ Mohammed Seyedhamzeh, ${ }^{[a]}$ Mehran Razeghi, ${ }^{[a]}$ \\ Carmen Najera, ${ }^{*[b]}$ and Mohsen Kompany-Zareh ${ }^{[a]}$
}

\begin{abstract}
Magnetic $\mathrm{Fe}_{3} \mathrm{O}_{4}$ nanoparticles (NPs) functionalized with carbon dots (C-dots) that contain carboxylic acid and hydroxyl groups were synthesized successfully and used for the reduction of $\mathrm{Pd}^{\prime \prime}$ and the formation of Pd NPs. The new material was characterized by SEM, TEM, energy-dispersive spectroscopy, solid UV spectroscopy, vibrating sample magnetometry, XRD, and X-ray photoelectron spectroscopy and was used as a very efficient catalyst in the Suzuki-Miyaura cross-coupling reaction of aryl bromides and chlorides with arylboronic acids in aqueous
\end{abstract}

media. Design of experiments indicates that the use of $0.22 \mathrm{~mol} \%$ of $\mathrm{Pd}, \mathrm{K}_{2} \mathrm{CO}_{3}$ as the base, and aqueous ethanol are the best reaction conditions. The reactions of aryl bromides take place at room temperature, and aryl chlorides react at $80^{\circ} \mathrm{C}$. The easily synthesized and air-stable catalyst Pd@Cdots@Fe $\mathrm{O}_{4}$ NPs could be separated from the reaction mixture by using an external magnet and reused in eight consecutive runs with $\square$ no significant loss of $\square$ catalytic activity.

\section{Introduction}

口Change to title ok? $\mathbf{D}$ Pd-catalyzed cross-coupling reactions are very important and powerful strategies for the formation of $\mathrm{C}-\mathrm{C}$ and $\mathrm{C}$-heteroatom bonds. ${ }^{[1]}$ As a result of the toxicity and high price of $\mathrm{Pd}$, in recent years, interest has grown in the organization and use of recoverable heterogeneous $\mathrm{Pd}$ catalysts. ${ }^{[2]}$ For this purpose, different solid materials such as modified silicas, ${ }^{[3]}$ polymers, ${ }^{[4]}$ mesoporous materials, ${ }^{[5]}$ ionic liquids, $^{[6]}$ and natural supports ${ }^{[7]}$ have been designated as supports for the heterogenization of Pd catalysts. Even with significant achievements in this area, the separation and efficient recovery of the heterogeneous catalyst from the reaction medium by conventional methods such as filtration or centrifugation is not always an easy assignment. One of the best methods to solve this problem is the use of magnetic nanoparticles (NPs) of $\mathrm{Fe}_{3} \mathrm{O}_{4}$ as a very convenient support for heterogenization of Pd catalysts. ${ }^{[8]}$ Very simple isolation and recovery, high surface area, and low toxicity are the key advantages of magnetic-NP-supported catalysts.

[a] M. Gholinejad, M. Seyedhamzeh, M. Razeghi, M. Kompany-Zareh Department of Chemistry, Institute for Advanced Studies in Basic Sciences (IASBS)

P. O. Box 45195-1159, Gavazang, Zanjan 45137-6731 (Iran)

E-mail:gholinejad@iasbs.ac.ir

[b] Prof. C. Najera

Departamento de Química Orgánica and Centro de Innovación en Química Avanzada (ORFEO-CINQA), Universidad de Alicante Apdo. 99, E-03080-Alicante (Spain)

E-mail:cnajera@ua.es

$\square$ Supporting Information for this article is available on the WWW under http://dx.doi.org/10.1002/cctc.201500925.
Recently, carbon quantum nanodots (C-dots) have been described as a new class of carbon structures with interesting properties. They are green, nontoxic, abundant, and inexpensive materials. In addition, C-dots have unique properties such as photostability and fluorescence emission, and for these reasons have been considered in different applications such as biosensing, bioimaging, light emitting diodes, fluorescent ink, and photocatalysis. ${ }^{[9,10]}$ Different methods such as laser ablation, pyrolysis, wet oxidation, ultrasound- and microwave-assisted synthesis, hydrothermal synthesis, and electrochemical etching have been developed for the synthesis of C-dots. ${ }^{[8,9]}$ The carboxylic and hydroxyl moieties of the C-dots confer excellent water solubility as well as biocompatibility and give them promise as an excellent support for catalyst stabilization. However, compared to other carbon structures such as carbon nanotubes and graphene, ${ }^{[11]}$ less attention has been paid to the use of C-dots as solid supports for catalysis design. Recently, C-dots-reduced Pd NPs have been reported as an efficient catalyst in Suzuki and Heck coupling reactions in water. ${ }^{[12]}$ However, to the best of our knowledge, there are no reports that deal with the modification of $\mathrm{Fe}_{3} \mathrm{O}_{4}$ NPs using C-dots and its application for stabilization of Pd NPs. In continuation of our interest into magnetically separable heterogeneous Pd catalysts, ${ }^{[13]}$ herein, we wish to report for the first time the synthesis and characterization of Pd NPs supported on magnetite NPs modified with C-dots and its application as a sustainable catalyst in the Suzuki-Miyaura cross-coupling reaction in aqueous media. 


\section{Results and Discussion}

$\mathrm{Fe}_{3} \mathrm{O}_{4}$ NPs were prepared in a coprecipitation step based on the procedure of Massart using $\mathrm{FeCl}_{3} \cdot 6 \mathrm{H}_{2} \mathrm{O}$ and $\mathrm{FeCl}_{2} \cdot 4 \mathrm{H}_{2} \mathrm{O}$. ${ }^{[14]}$ $\mathrm{C}$-dots were prepared following a procedure described previously using a mixture of citric acid and urea that was transferred to a Teflon autoclave and heated at $160^{\circ} \mathrm{C}$ for $6 \mathrm{~h}^{[15 \mathrm{a}]}$ The obtained $\mathrm{C}$-dots were treated with $\mathrm{Fe}_{3} \mathrm{O}_{4} \mathrm{NPs}$ at $60^{\circ} \mathrm{C}$ for $24 \mathrm{~h}$ to afford C-dots@ $\mathrm{Fe}_{3} \mathrm{O}_{4}$ NPs. The final Pd@C-dots@ $\mathrm{Fe}_{3} \mathrm{O}_{4}$ catalyst was obtained simply by dissolving $\mathrm{PdCl}_{2}$ in water by sonication and the addition of C-dots@ $\mathrm{Fe}_{3} \mathrm{O}_{4}$, also dissolved in water by sonication, and heating at $60^{\circ} \mathrm{C}$ for 1 day. The loading of $\mathrm{Pd}$ in the obtained material was determined by inductively coupled plasma (ICP) analysis to be $0.27 \mathrm{mmolg}^{-1}$. Thermogravimetric analysis (TGA) of the prepared material showed two major weights loses between 25 and $700^{\circ} \mathrm{C}$. The first weight loss, which occurs between 25 and $100^{\circ} \mathrm{C}$, is related to water and physically adsorbed solvents. The second weight loss, which occurred between 100 and $700{ }^{\circ} \mathrm{C}$, may be related to the C-dots on the $\mathrm{Fe}_{3} \mathrm{O}_{4}$ NPs (Figure 1).

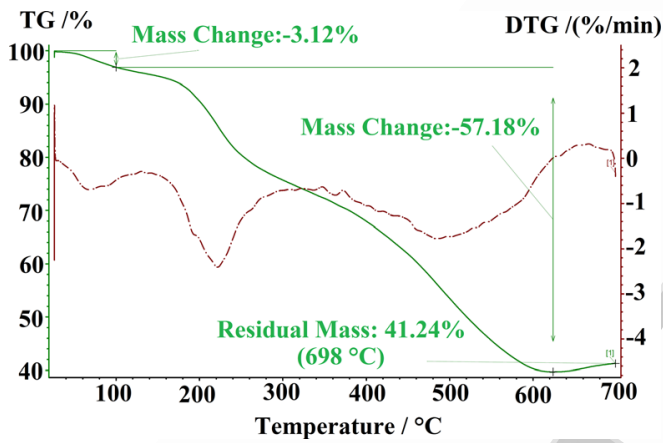

Figure 1.TGA profile of Pd@C-dots@ $\mathrm{Fe}_{3} \mathrm{O}_{4}$.

FTIR spectroscopy provided further confirmation that the surface of the magnetic NPs was modified by C-dots (Figure 1, Supporting information). The absorption bands at $\tilde{v}=3000$ $3500 \mathrm{~cm}^{-1}$ are assigned to the stretching vibrations of $\mathrm{OH}$ and $\mathrm{NH}_{2}$ groups, and a peak at $\tilde{v}=1622 \mathrm{~cm}^{-1}$ can be assigned to the $\mathrm{C}=\mathrm{O}$ band.

XRD analysis of the prepared material showed the formation of $\mathrm{Pd}^{0} \mathrm{NPs}$ on the $\mathrm{C}$-dot@ $\mathrm{Fe}_{3} \mathrm{O}_{4}$ surface by the appearance of Bragg's reflections related to $\mathrm{Fe}_{3} \mathrm{O}_{4} \mathrm{NPs}^{[16]}$ at $2 \theta=30.17,35.46$, $43.38,53.69,57.23$, and $62.77^{\circ}$ and those related to Pd NPs ${ }^{[17]}$ at $2 \theta=40.1,46.7$, and $68.1^{\circ}$ (Figure 2).

The reduction of $\mathrm{Pd}^{\prime \prime}$ to $\mathrm{Pd}^{0}$ was also confirmed by diffuse reflectance UV/Vis (DR UV/Vis) spectroscopy from the disappearance of the peak related to $\mathrm{PdCl}_{2}$ at $\lambda=280 \mathrm{~nm}$ in the spectrum of Pd@C-dots@ $\mathrm{Fe}_{3} \mathrm{O}_{4}$ (Figure 3). ${ }^{[18]}$

However, to obtain exact information about the oxidation state of Pd species, X-ray photoelectron spectroscopy (XPS) was performed (Figure 4). Results showed the presence of an intense doublet at a binding energy (BE) of 335.6 and $340.8 \mathrm{eV}$ related to $\mathrm{Pd}^{0}$ and peaks at $\mathrm{BE}=338$ and $343 \mathrm{eV}$ related to $\mathrm{Pd}^{\prime \prime}$, which correspond to the $\mathrm{Pd} 3 \mathrm{~d}_{5 / 2}$ and $\mathrm{Pd} 3 \mathrm{~d}_{3 / 2}$ peaks, respec-

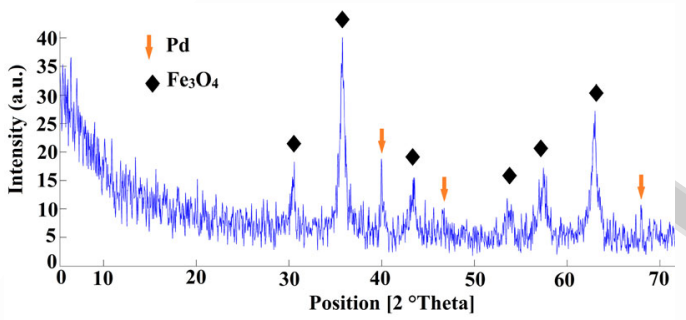

Figure 2. XRD pattern of Pd@C-dots@Fe3O4.

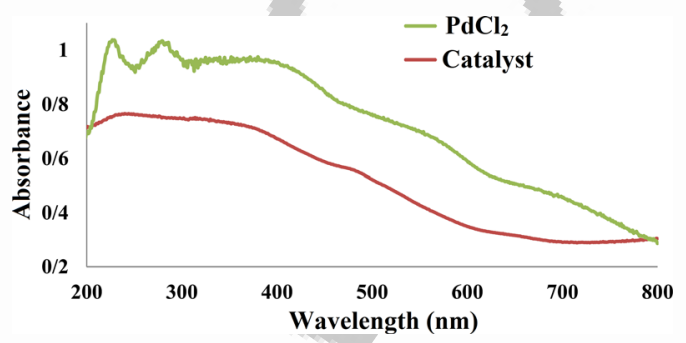

Figure 3. DR UV/Vis spectra of $\mathrm{PdCl}_{2}$ and Pd@C-dots@Fe $\mathrm{O}_{3}$.

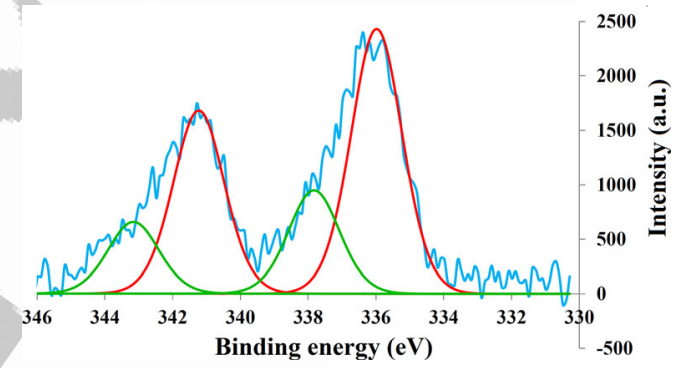

Figure 4. XPS spectrum of $\mathrm{Pd} @ \mathrm{C}-\mathrm{dots} @ \mathrm{Fe}_{3} \mathrm{O}_{4}$ in the $\mathrm{Pd} 3 \mathrm{~d}$ region.

tively. These results indicate that most of the Pd is present in the reduced form, which confirms the capability of C-dots@$\mathrm{Fe}_{3} \mathrm{O}_{4}$ in the efficient reduction of $\mathrm{Pd}^{\text {II }}$ to $\mathrm{Pd}^{0} \mathrm{NPs} .{ }^{[19]}$

Moreover, the presence of carbon in the structure of Pd@Cdots@ $\mathrm{Fe}_{3} \mathrm{O}_{4}$ confirmed by XPS analysis by the appearance of peaks related to $\mathrm{C} 1 \mathrm{~s}$ at $\mathrm{BE}=283.87 \mathrm{eV}$ for graphitic or aliphatic carbon, $\mathrm{BE}=286.13 \mathrm{eV}$ for oxygenated carbon, and $\mathrm{BE}=$ $287.75 \mathrm{eV}$ for nitrous forms of carbon (Figure 5). ${ }^{[15]}$

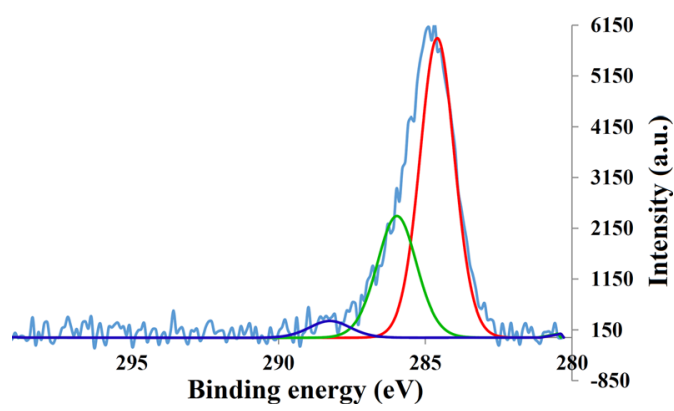

Figure 5. XPS spectrum of $\mathrm{Pd} @ \mathrm{C}-$ dots $@ \mathrm{Fe}_{3} \mathrm{O}_{4}$ in the $\mathrm{C} 1 \mathrm{~s}$ region. 


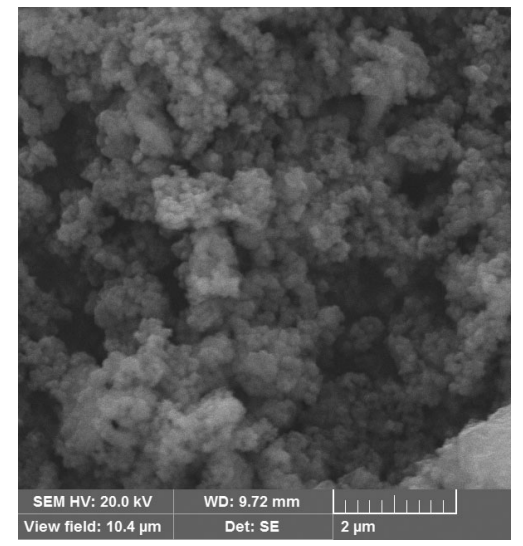

Figure 6. SEM image of Pd@C-dots@ $\mathrm{Fe}_{3} \mathrm{O}_{4}$

SEM images of the Pd@C-dots@ $\mathrm{Fe}_{3} \mathrm{O}_{4}$ showed the formation of uniform spherical particles (Figure 6), and the energy-dispersive spectrum (EDS) obtained from SEM confirmed the presence of $\mathrm{Pd}, \mathrm{Fe}$, and $\mathrm{C}$ species in the structure of the material (Figure 7). Furthermore, TEM images of the material at different magnifications showed the nanostructure character of the prepared material of an average size of $20 \mathrm{~nm}$ and showed the presence of carbon shells in the structure (Figure 8).

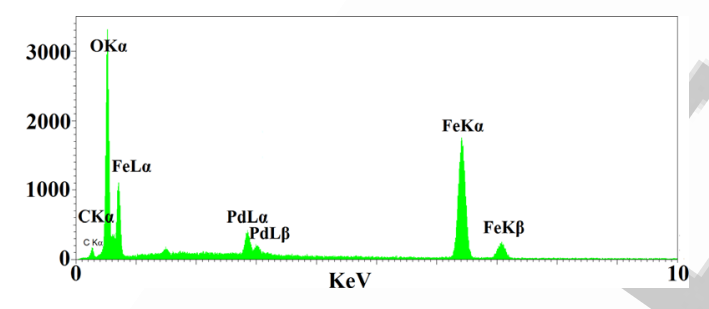

Figure 7. EDS spectrum of Pd@C-dots@ $\mathrm{Fe}_{3} \mathrm{O}_{4}$ obtained from SEM.

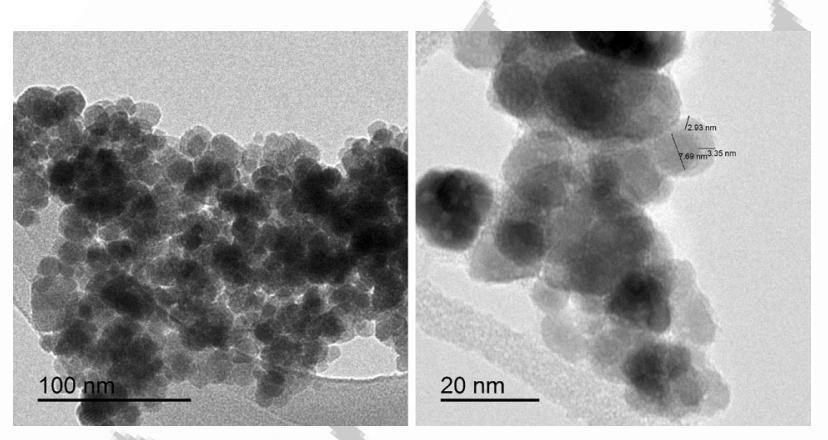

Figure 8. TEM image of Pd@C-dots@ $\mathrm{Fe}_{3} \mathrm{O}_{4}$ at different magnifications.

The superparamagnetic character of Pd@C-dots@ $\mathrm{Fe}_{3} \mathrm{O}_{4}$ and $\mathrm{Fe}_{3} \mathrm{O}_{4} \mathrm{NPs}$ was also studied. Results showed that the decrease in the magnetization value of the Pd@C-dots@ $\mathrm{Fe}_{3} \mathrm{O}_{4}$ (50 em $\mu^{-1} \square$ units ok? $\square$ ) in comparison with that of $\mathrm{Fe}_{3} \mathrm{O}_{4} \mathrm{NPs}\left(64 \mathrm{em} \mathrm{\mu g}^{-1}\right)$ confirms the modification of $\mathrm{Fe}_{3} \mathrm{O}_{4} \mathrm{NPs}$ with C-dots (Figure 9). Zero coercivity, remanence on the mag-

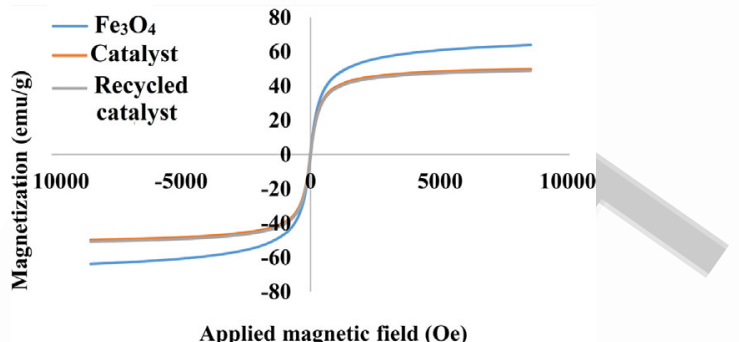

Figure 9. Magnetization values.

netization loop, and the absence of a hysteresis loop in both samples confirmed the superparamagnetic properties and the ease of separation of the material from the reaction mixture.

The catalytic activity of the prepared Pd@C-dots@ $\mathrm{Fe}_{3} \mathrm{O}_{4}$ was evaluated in the Suzuki-Miyaura coupling reaction of aryl bromides and chlorides. To find the optimized reaction conditions, design of experiments (DoE) ${ }^{[20]}$ for the reaction of 4-bromoanisol and phenylboronic acid as a model reaction was pursued. A five-level, three-factor central composite design to study of the effect of the parameters on coupling reaction was created (Table S1). The three independent variables (factors) are the solvent type $\left(X_{1}\right)$, base type $\left(X_{2}\right)$, and the amount of catalyst $\left(X_{3}\right)$. The regression coefficients obtained from the mathematical linear second-order model [Eq. (1), Supporting Information] are given in Table S2. From the results of Table S2, a secondorder mathematical model [Eq. (2)] was generated. After we substituted regression coefficients into Equation (1), a new equation that involved $Y$ (reaction yield), $X_{1}, X_{2}$, and $X_{3}$ was obtained.

$Y=89.8515+7.2724 X_{1}+2.3165 X_{2}+2.3764 X_{3}$
$+6.6250 X_{1} X_{2}-0.3750 X_{1} X_{3}-1.1250 X_{2} X_{3}-29.9348 X_{1}{ }^{2}$
$-28.6974 X_{2}{ }^{2}-1.1202 X_{3}{ }^{2}$

We used statistical analysis of variance (ANOVA) significance and fitness of the model as well as the effects of significant individual terms and their interactions to study the chosen responses (Tables S2 and S3).

Usually, the parameters with $p<0.05$ are considered as significant parameters, and a correlation factor $R^{2}>0.85$ is desired for the mathematical model to be considered as a good approximation of the reaction. The type of solvent, quadratic term of the solvent, quadratic term of the base, and solventbase interaction term were significant model terms (Table S2). The results show that the effect of the type of solvent is dependent on the type of base applied in the reaction. In addition, the effects of catalyst and the quadratic term of catalystbase and catalyst-solvent interactions were insignificant. The insignificant effect of catalysis does not mean that catalysis has no effect on the reaction rate. It means that a change in concentration of the catalyst has no significant effect compared to that of the type of solvent and applied base. Insignificant terms can be removed from the model manually to improve the regression model and optimization results [Eq. (3)]. 
$Y=89.8515+7.2724 X_{1}+16.6250 X_{1} X_{2}-0.3750 X_{1} X_{3}$

$-1.1250 X_{2} X_{3}-29.9348 X_{1}^{2}-28.6974 X_{2}^{2}$

Eq.(3)

We used Equation (3) to plot a 3D graph of the secondorder Suzuki coupling reaction (Figure 10). The yield of the reaction increased in the middle of the diagram (dark red), which indicates the use of $\mathrm{EtOH} / \mathrm{H}_{2} \mathrm{O}$ as the solvent and $\mathrm{K}_{2} \mathrm{CO}_{3}$ as the base. Furthermore, a contour plot diagram obtained from the $3 \mathrm{D}$ graph confirmed that the best reaction yield could be obtained using $\mathrm{EtOH} / \mathrm{H}_{2} \mathrm{O}$ as the solvent and $\mathrm{K}_{2} \mathrm{CO}_{3}$ as the base (Figure 11).

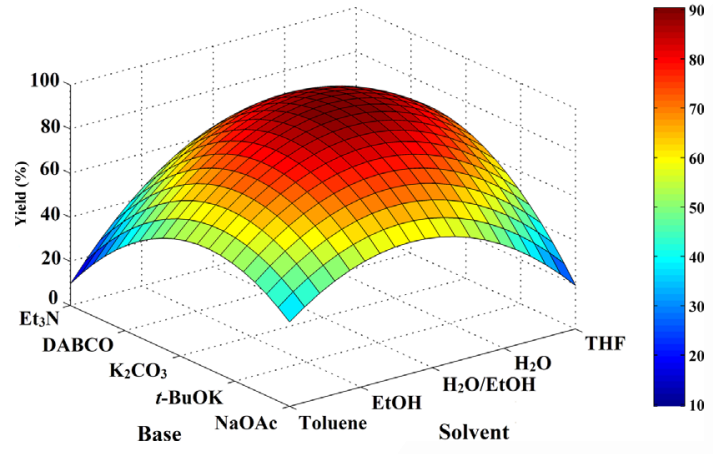

Figure 10.3D graph of the second-order reaction to model the Suzuki coupling.

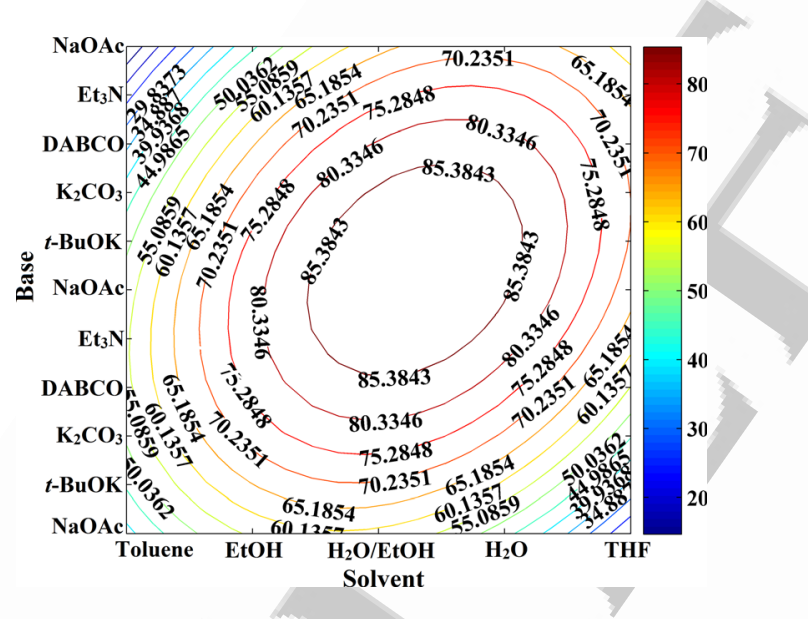

Figure 11. Contour plot diagram obtained from the 3D graph.

Notably, 3D graphs and their corresponding contour plots for the base with respect to the amount of catalyst and also the solvent with respect to the catalyst amount indicated that the use of $0.22 \mathrm{~mol} \%$ of $\mathrm{Pd}, \mathrm{EtOH} / \mathrm{H}_{2} \mathrm{O}$ as the solvent, and $\mathrm{K}_{2} \mathrm{CO}_{3}$ as the base are the best reaction conditions. The model reaction under the optimized reaction conditions was also studied without the catalyst, but only $3 \%$ conversion to the product was observed. Under the optimized reaction conditions, the reactions of structurally different aryl bromides and chlorides with different arylboronic acids were studied in the presence of the catalyst (Table 1). The results indicate that aryl bromides that contain electron-donating groups, such as $4-\mathrm{OH}$,
4-OMe, and 4-Me, as well as electron-withdrawing groups, such as $4-\mathrm{NO}_{2}, 4-\mathrm{Cl}, 4-\mathrm{CN}, 4-\mathrm{CHO}$, and 2-CHO, with phenylboronic acid proceeded satisfactorily, and the corresponding coupling products were obtained in high to excellent yields (Table 1, entries 1-11). Moreover, reactions of unsubstituted aryl bromides, such as bromobenzene, bromobiphenyl, and 1bromonaphthalene, proceed efficiently and afford the corresponding products (Table 1, entries 1, 12 and 13). The reaction of 5-bromopyrimidine as a heterocyclic aryl bromide with phenylboronic acid gave the coupling product in $98 \%$ isolated yield (Table 1, entry 2). Substituted aryl chlorides are less expensive than aryl bromides and more accessible for Pd-catalyzed cross-coupling reactions. However, the reactions of aryl chlorides under the optimized reaction conditions at room temperature were sluggish, therefore, the reaction temperature was increased to $80^{\circ} \mathrm{C}$. Under these reaction conditions, the Suzuki-Miyaura reaction was efficient, and the desired cross-coupling products were obtained in high to excellent yields (Table 1, entries 18-22).

To show the importance of the C-dots in the activation and stabilization of Pd NPs, a similar catalyst without C-dots was synthesized. Pd absorbed physically on $\mathrm{Fe}_{3} \mathrm{O}_{4} \mathrm{NPs}$ was tested in the model reaction under the optimized reaction conditions. However, the results showed that reaction achieved only $14 \%$ GC yield in $24 \mathrm{~h}$. This result confirms the key role of C-dots for the reduction and formation of reactive Pd NPs in the catalyst structure.

One of the main advantages of magnetite-NPs-supported catalysts is the easy separation and recycling of the catalyst. To study the recycling properties of this catalyst, the reaction of 5-bromopyrimidine with phenylboronic acid under the optimized reaction conditions was selected. The results showed that the catalyst is recyclable in eight consecutive runs just by decantation with a magnetic bar $\mathbf{\square}$ with no significant loss of $\mathbf{\square}$ catalytic activity (Figure 12).

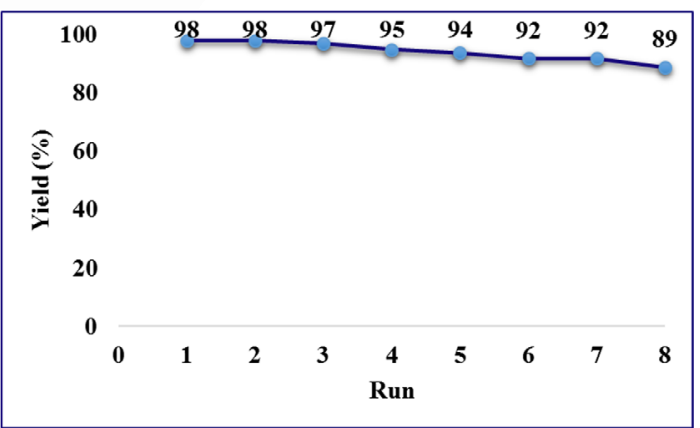

Figure 12. Recycling experiments for the cross-coupling of 5-bromopyrimidine and phenylboronic acid.

The leaching of $\mathrm{Pd}$ into the reaction solution after eight runs was determined by ICP analysis to be $1.26 \%$, which indicates the stability of the catalyst during the reaction. In addition, SEM (Figure 13) and TEM (Figure 14) images of the catalyst after the third run showed that the nanostructure of the catalyst was preserved. 


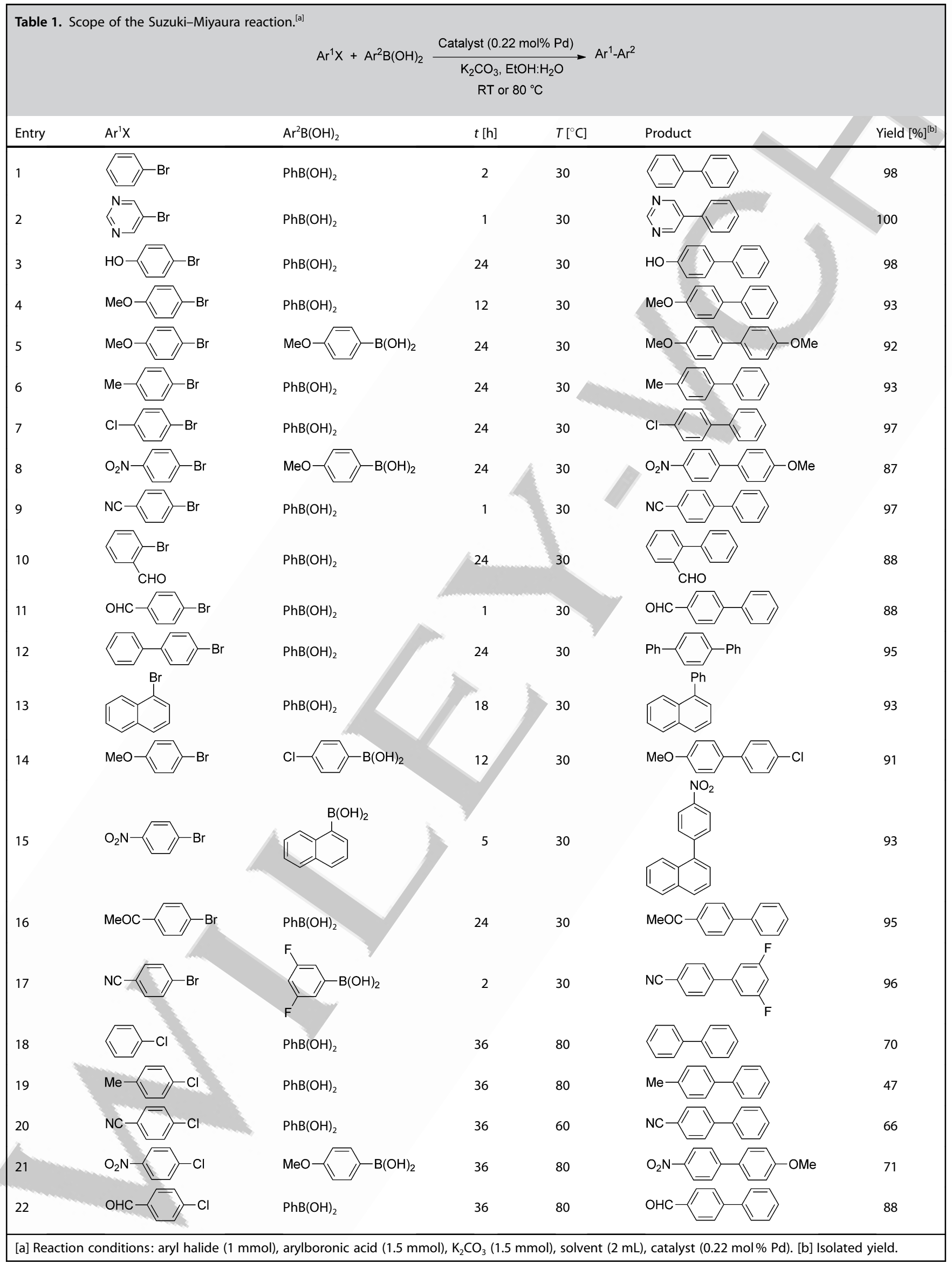




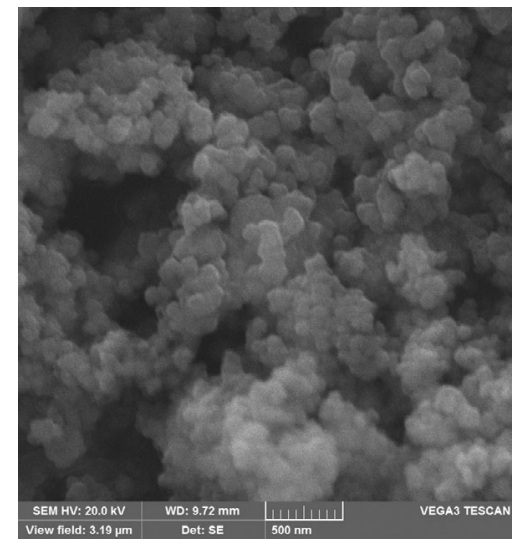

Figure 13. SEM image of the catalyst after the third run.

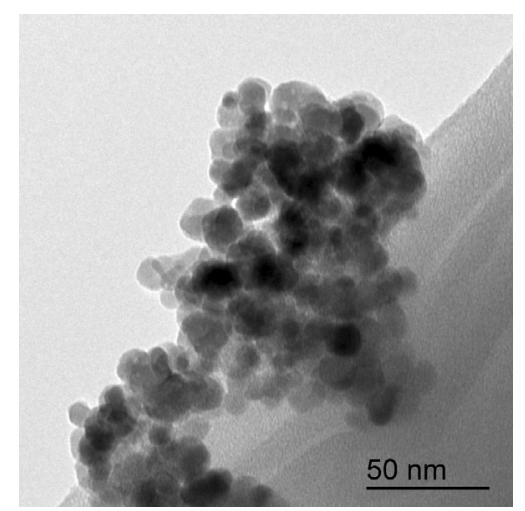

Figure 14. TEM image of reused catalyst after the third run.

Furthermore, a study of the magnetization of the recycled catalyst after the third run (Figure 9) confirmed the preservation of the superparamagnetic properties of the catalyst during the reaction.

\section{Conclusions}

We have introduced a new magnetically separable $\mathrm{Pd}$ catalyst, in which magnetic $\mathrm{Fe}_{3} \mathrm{O}_{4}$ was modified by carbon dots as a green and abundant material to support $\mathrm{Pd}$ nanoparticles (NPs). The new material can reduce $\mathrm{PdCl}_{2}$ to $\mathrm{Pd}$ NPs without the use of another reducing agent. The obtained catalyst was characterized successfully by different techniques, such as energy-dispersive spectroscopy, TEM, thermogravimetric analysis, FTIR spectroscopy, vibrating sample magnetometry, atomic absorption spectroscopy, and solid UV/Vis spectroscopy, and has been applied successfully as an efficient catalyst for the Suzuki-Miyaura cross-coupling reaction in aqueous media (aqueous ethanol). The exact amount of required catalyst and type of solvent and base were determined using design of experiments. The reactions of aryl bromides were performed at room temperature, and that of aryl chlorides at $80^{\circ} \mathrm{C}$. Comparative studies with physically absorbed $\mathrm{Pd}$ on $\mathrm{Fe}_{3} \mathrm{O}_{4} \mathrm{NPs}$ showed a very low catalytic efficiency with respect to Pd@Cdots@ $\mathrm{Fe}_{3} \mathrm{O}_{4}$. The catalyst was recycled easily using a magnetic bar in eight consecutive runs $\mathbf{\square}$ with no significant loss of catalytic activity and its structure and the superparamagnetic properties were retained.

\section{Experimental Section}

\section{Synthesis of magnetic NPs ${ }^{[14]}$}

$\mathrm{FeCl}_{3} \cdot 6 \mathrm{H}_{2} \mathrm{O}(11.0 \mathrm{~g})$ and $\mathrm{FeCl}_{2} \cdot 4 \mathrm{H}_{2} \mathrm{O}(4.0 \mathrm{~g})$ were dissolved in deionized water $(250 \mathrm{~mL})$ and the mixture was stirred using a mechanical stirrer under an $\mathrm{Ar}$ atmosphere. To the resulting mixture, aqueous ammonia $(25 \%, 40 \mathrm{~mL})$ was added slowly over $20 \mathrm{~min}$, and the mixture was stirred at $80^{\circ} \mathrm{C}$ for $4 \mathrm{~h}$. A black precipitate of $\mathrm{Fe}_{3} \mathrm{O}_{4}$ was collected by using an external magnet and washed with deionized water $(3 \times 20 \mathrm{~mL})$ and ethanol $(3 \times 20 \mathrm{~mL})$ and finally dried under vacuum.

\section{Synthesis of carbon-dots-modified $\mathrm{Fe}_{3} \mathrm{O}_{4}$}

Citric acid $(1 \mathrm{~g})$ and urea $(0.5 \mathrm{~g})$ were dissolved in distilled water $(25 \mathrm{~mL})$, and the mixture was transferred to a Teflon autoclave and heated at $160^{\circ} \mathrm{C}$ for $6 \mathrm{~h}$. Then, the reactor was cooled to RT, and the obtained material was centrifuged at $10000 \mathrm{rpm}$ for $10 \mathrm{~min}$ to remove larger particles. $\mathrm{Fe}_{3} \mathrm{O}_{4} \mathrm{NPs}(0.5 \mathrm{~g})$ were sonicated in water $(5 \mathrm{~mL})$ for $15 \mathrm{~min}$. Then, the $\mathrm{C}$-dots suspension $(0.7 \mathrm{~mL})$ was added to the flask that contained the magnetic particles, and this mixture was stirred mechanically for $24 \mathrm{~h}$ at $60^{\circ} \mathrm{C}$. The resulting carbondots-modified $\mathrm{Fe}_{3} \mathrm{O}_{4}$ was subjected to magnetic separation and the obtained material was washed with deionized water $(3 \times 10 \mathrm{~mL})$ and ethanol $(3 \times 10 \mathrm{~mL})$ and dried under vacuum.

\section{Synthesis of Pd@C-dots@ $\mathrm{Fe}_{3} \mathrm{O}_{4}$}

C-dots@ $\mathrm{Fe}_{3} \mathrm{O}_{4}(500 \mathrm{mg})$ was sonicated in water $(10 \mathrm{~mL})$ for $30 \mathrm{~min}$ at RT. In another flask, $\mathrm{PdCl}_{2}(60 \mathrm{mg})$ was sonicated and dissolved in water $(5 \mathrm{~mL})$. Then, the solution of $\mathrm{PdCl}_{2}$ was added to the flask that contained C-dots@ $\mathrm{Fe}_{3} \mathrm{O}_{4}$, and the mixture was mechanically stirred for $24 \mathrm{~h}$ at $60^{\circ} \mathrm{C}$ under reflux. Then, the solid was separated magnetically, washed with water $(3 \times 20 \mathrm{~mL})$ and ethanol $(3 \times$ $20 \mathrm{~mL}$ ), and dried in an oven at $60^{\circ} \mathrm{C}$. The loading of Pd on the obtained material was determined by ICP analysis to be $0.275 \mathrm{mmol} \mathrm{g}^{-1}$.

\section{General procedure for the Suzuki-Miyaura reaction}

Aryl halide $(1 \mathrm{mmol})$, arylboronic acid $(1.5 \mathrm{mmol}), \mathrm{K}_{2} \mathrm{CO}_{3}(1.5 \mathrm{mmol})$, catalyst ( $8 \mathrm{mg}$ that contained $0.22 \mathrm{~mol} \% \mathrm{Pd}$ ) and water/ethanol $(1: 1,2 \mathrm{~mL})$ were added to a $5 \mathrm{~mL}$ flask, and the mixture was stirred mechanically at RT or $80^{\circ} \mathrm{C}$ (depending on the aryl halide). The progresses of the reactions were monitored by GC. After completion of the reaction, the crude product was extracted using ethyl acetate. The pure products were obtained by column chromatography on silica using the hexane and ethyl acetate as eluent.

\section{Acknowledgements}

The authors are grateful to the Institute for Advanced Studies in Basic Sciences (IASBS) and the Iran National Science Foundation (INSF-Grant number of 94010666) for support of this work. C.N. is grateful to the Spanish Ministerio de Economia y Competitividad (MINECO) (projects CTQ2013-43446-P and CTQ2014-51912-REDC), 
FEDER, the Generalitat Valenciana (PROMETEOII/2014/017), and the University of Alicante for financial support.

Keywords: cross-coupling • iron - nanoparticles · palladium · quantum dots

[1] a) Á. Molnár, Palladium-Catalyzed Coupling Reactions: Practical Aspects, Future Developments, Wiley-VCH, Weinheim, 2013; b) Á. Molnár, Chem. Rev. 2011, 111, 2251-2320; c) R. Jana, T. P. Pathak, M. S. Sigman, Chem. Rev. 2011, 111, 1417-1492; d) M. Lamblin, L. Nassar-Hardy, J. C. Hierso, E. Fouquet, F. X. Felpin, Adv. Synth. Catal. 2010, 352, 33-79; e) B. C. G. Söderberg, Coord. Chem. Rev. 2003, 241, 147-247; f) A. Fihri, M. Bouhrara, B. Nekoueishahraki, J.-M. Basset, V. Polshettiwar, Chem. Soc. Rev. 2011, 40, 5181-5203; g) V. Polshettiwar, A. Decottignies, C. Len, A. Fihri, ChemSusChem 2010, 3, 502-522.

[2] a) M. Pagliaro, V. Pandarus, F. Béland, R. Ciriminna, G. Palmisano, P. Demma Carà, Catal. Sci. Technol. 2011, 1, 736-739; b) C. J. Pink, H.-t. Wong, F. C. Ferreira, A. G. Livingston, Org. Process Res. Dev. 2008, 12, 589-595; c) Y. Yabe, Y. Sawama, Y. Monguch, H. Sajiki, Catal. Sci. Technol. 2014, 4, 260-271; d) M. Mora, C. Jiménez-Sanchidrián, J. R. Ruiz, Curr. Org. Chem. 2012, 16, 1128-1150; e) L. Yin, J. Liebscher, Chem. Rev. 2007, 107, 133 173; f) M. Pagliaro, V. Pandarus, R. Ciriminna, F. Béland, P. Demma Carà, ChemCatChem 2012, 4, 432-445.

[3] a) V. Polshettiwar, A. Molnár, Tetrahedron 2007, 63, 6949-6976; b) A Fihri, D. Cha, M. Bouhrara, N. Almana, V. Polshettiwar, ChemSusChem 2012, 5, 85-89.

[4] a) S. Navalón, M. Álvaro, H. García, ChemCatChem 2013, 5, 3460-3480; b) Y. Gong, M. Li, H. Li, Y. Wang, Green Chem. 2015, 17, 715-736.

[5] a) B. Karimi, H. Behzadnia, H. Vali, ChemCatChem 2014, 6, 745-748; b) R. Ali Molla, M. A. Iqubal, K. Ghosh, A. S. Roy, Kamaluddin, S. M. Islam, RSC Adv. 2014, 4, 48177-48190; c) P. Puthiaraj, K. Pitchumani, Green Chem. 2014, 16, 4223-4233; d) H. Veisi, A. Amini Manesh, N. Eivazi, A. R. Faraji, RSC Adv. 2015, 5, 20098-20107.

[6] a) F. Bellina, C. Chiappe, Molecules 2010, 15, 2211-2245; b) S. B. Park, H. Alper, Chem. Commun. 2004, 1306-1307; c) N. Iranpoor, H. Firouzabadi, Y. Ahmadi, Eur. J. Org. Chem. 2012, 2012, 305-311; d) P. Nehra, B. Khungar, K. Pericherla, S. C. Sivasubramaniana, A. Kumar, Green Chem. 2014, $16,4266-4271$.

[7] a) A. Ghaderi, M. Gholinejad, H. Firouzabadi, Curr. Org. Chem. 2015, 19 1-22; b) A. Hassine, M. Bouhrara, S. Sebti, A. Solhy, R. Mahfouz, D. Luart, C. Len, A. Fihri, Curr. Org. Chem. 2014, 18, $3141-3148$.

[8] a) B. Karimi, F. Mansouri, H. Mirzaei, Chem CatChem 2015, 7, 1736-1789; b) H. Veisi, J. Gholami, H. Ueda, P. Mohammadi, M. Noroozi, J. Mol. Catal. A 2015, 396, 216-223; c) S. Verma, D. Verma, A. K. Sinha, S. L. Jain, Appl.
Catal. A 2015, 489, 17-23; d) Z. Yinghuai, S. C. Peng, A. Emi, S. Zh. Monalisa, R. A. Kemp, Adv. Synth. Catal. 2007, 349, 1917-1922; e) C. G. Tan, R. N. Grass, Chem. Commun. 2008, 4297-4299; f) S. Shylesh, L. Wang, W. R. Thiel, Adv. Synth. Catal. 2010, 352, 425-432.

[9] S. Y. Lim, W. Shen, Z. Gao, Chem. Soc. Rev. 2015, 44, 362-381.

[10] Y. Wang, A. Hu, J. Mater. Chem. C 2014, 2, 6921-6939.

[11] a) R. Kannan, H.-R. Jang, E.-S. Yoo, H.-K. Lee, D. J. Yoo, RSC Adv. 2015, 5, 35993-36000; b) X. Wu, S. Gua, J. Zhang, Chem. Commun. 2015, 51, 6318-6321; c) X. Wang, L. Wang, F. Zhao, C. Hu, Y. Zhao, Z. Zhang, S. Chen, G. Shi, L. Qu, Nanoscale 2015, 7, 3035-3042; d) Ch.-Ch. Wang, S.Y. Lu, Nanoscale 2015, 7, 1209-1215; e) H. Li, C. Sun, M. Ali, F. Zhou, X. Zhang, D. R. MacFarlane, Angew. Chem. Int. Ed. 2015, 54, 8420-8424; Angew. Chem. 2015, 127, 8540-8544; f) S. Liu, J. Tian, L. Wang, Y. Luo, X. Sun, RSC Adv. 2012, 2, 411-413; g) A. Ohtaka, J. M. Sansano, C. Nájera, I. M. García, Á. Berenguer-Murcia, D. Cazorla-Amorós, ChemCatChem 2015, 7, 1841-1847.

[12] D. Dey, T. Bhattacharya, B. Majumdar, S. Mandani, B. Sharma, T. K. Sarma, Dalton Trans. 2013, 42, 13821-13825.

[13] a) H. Firouzabadi, N. Iranpoor, M. Gholinejad, J. Hoseini, Adv. Synth Catal. 2011, 353, 125-132; b) H. Firouzabadi, N. Iranpoor, M. Gholinejad, S. Akbar, N. Jeddi, RSC Adv. 2014, 4, 17060-17070; c) M. Gholinejad, M. Razeghi, C. Nájera, RSC Adv. 2015, 5, 49568-49576; d) M. Gholinejad, J. Ahmadi, ChemPlusChem 2015, 80, 973-979; e) M. Gholinejad, A. Aminianfar, J. Mol. Catal. A 2015, 397, 106-113; f) M. Gholinejad, B. Karimi, F. Mansouri, J. Mol. Catal. A 2014, 386, 20-26; g) M. Gholinejad, H. Firouzabadi, New J. Chem. 2015, 39, 5953-5959.

[14] R. Massart, IEEE Trans. Magn. 1981, 17, 1247-1248.

[15] a) X. M. Li, S. L. Zhang, S. A. Kulinich, Y. L. Liu, H. B. Zeng, Sci. Rep. 2014, 4, 4976; b) S. Liu, J. Tian, L. Wang, Y. Zhang, X. Qin, Y. Luo, A. M. Asiri, A. O. Al-Youbi, X. P. Sun, Adv. Mater. 2012, 24, 2037-2041.

[16] S. Li, W. Zhang, M.-H. So, C.-M. Che, R. Wang, R. Chen, J. Mol. Catal. A 2012, 359, 81-87.

[17] M. Gholinejad, F. Hamed, P. Biji, Dalton Trans. 2015, 44, 14293- 14303.

[18] a) K. K. R. Datta, M. Eswaramoorthy, C. N. R. Rao, J. Mater. Chem. 2007, $17,613-615$; b) H. Firouzabadi, N. Iranpoor, A. Ghaderi, M. Gholinejad, S. Rahimi, S. Jokar, RSC Adv. 2014, 4, 27674-27682.

[19] J. Sun, Y. Fu, G. He, X. Sun, X. Wang, Catal. Sci. Technol. 2014, 4, $1742-$ 1748.

[20] a) V. K. Aggarwal, A. C. Staubitz, M. Owen, Org. Process Res. Dev. 2006, 10, 64-69; b) K. B. Sidhpuria, A. L. Daniel-da-Silva, T. Trindade, J. A. P. Coutinho, Green Chem. 2011, 13, 340-349.

Received: August 18, 2015

Published online on $\mathbf{\square} \mathbf{~ H}, 0000$ 


\section{FULL PAPERS}

M. Gholinejad, ${ }^{*}$ M. Seyedhamzeh,

M. Razeghi, C. Najera,*

M. Kompany-Zareh

$\square-\square$

Iron Oxide Nanoparticles Modified with Carbon Quantum Nanodots for the Stabilization of Palladium Nanoparticles: An Efficient Catalyst for the Suzuki Reaction in Aqueous Media under Mild Conditions

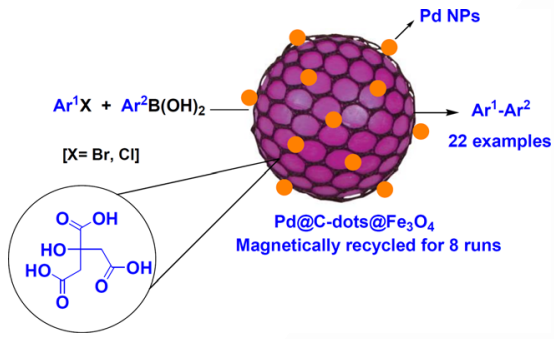

Dot to dot: Pd supported on $\mathrm{Fe}_{3} \mathrm{O}_{4}$ nanoparticles modified with carbon quantum nanodots is shown to be an efficient catalyst for Suzuki coupling reactions.

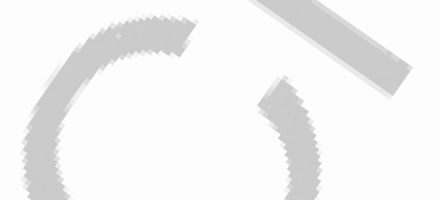

Modified iron oxide nanoparticles stabilize Pd nanoparticles for \#catalysis @UA Universidad SPACE RESERVED FOR IMAGE AND LINK

Share your work on social media! ChemCatChem has added Twitter as a means to promote your article. Twitter is an online microblogging service that enables its users to send and read text-based messages of up to 140 characters, known as "tweets". Please check the pre-written tweet in the galley proofs for accuracy. Should you or your institute have a Twitter account, please let us know the appropriate username (i.e., @accountname), and we will do our best to include this information in the tweet. This tweet will be posted to the journal's Twitter account @ChemCatChem (follow us!) upon online publication of your article, and we recommended you to repost ("retweet") it to alert other researchers about your publication.

Please check that the ORCID identifiers listed below are correct. We encourage all authors to provide an ORCID identifier for each coauthor. ORCID is a registry that provides researchers with a unique digital identifier. Some funding agencies recommend or even require the inclusion of ORCID IDs in all published articles, and authors should consult their funding agency guidelines for details. Registration is easy and free; for further information, see http://orcid.org/.

Mohammad Gholinejad

Mohammed Seyedhamzeh

Mehran Razeghi

Carmen Najera

Mohsen Kompany-Zareh

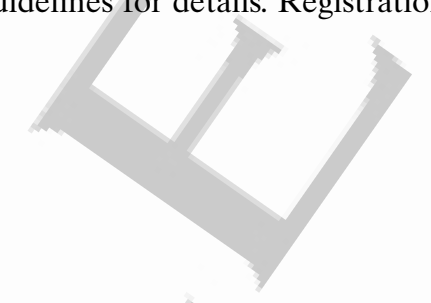

